\title{
Qualidade física, fisiológica e superação de dormência de sementes de umbuzeiro (Spondias tuberosa Arr. Câmara)
}

\author{
Physical, physiological quality and superation of numbness of \\ umbuzeiro (Spondias tuberosa Arr. Câmara) seeds
}

Danúbia Aparecida Costa Nobre ${ }^{1}$, Izabel Costa Silva Neta ${ }^{2}$, Victor Martins Maia ${ }^{3}$,

Andréia Márcia Santos de Souza David ${ }^{3}$, Rodrigo Sobreira Alexandre ${ }^{4}$

'Departamento de Fitotecnia, Universidade Federal de Viçosa (UFV) Viçosa, MG, Brasil

${ }^{2}$ Departamento de Fitotecnia, Universidade Federal de Lavras (UFLA), Campus Universitário, Caixa Postal 3037. CEP 37200-000, Lavras, MC Brasil

3Departamento de Ciências Agrárias, Universidade Estadual de Montes Claros (Unimontes), Campus de Janaúba, Janaúba, MG, Brasil ¿Departamento de Ciências Agrárias e Biolōgicas, Universidade Federal do Espírito Santo, Campus São Mateus, São Mateus, ES, Brasil

*autor correspondente 凹izabel_agronomia@hotmail.com
RESUMO: Um dos fatores que afetam a propagação do umbuzeiro (Spondias tuberosa Arr. Câmara) é a dormência de suas sementes, que promove uma emergência lenta e desuniforme. Dessa forma, o objetivo do estudo foi avaliar os possíveis métodos para superação da dormência de sementes de umbuzeiro (Spondias tuberosa Arr. Câmara) e a qualidade física e fisiológica delas. Foram realizados os seguintes testes e determinações: teor de água, massa de 100 sementes, comprimento e largura de sementes, emergência das plântulas, índice de velocidade de emergência, matéria fresca e seca de plântulas. O delineamento utilizado foi inteiramente casualizado com 4 repetições de 50 sementes por tratamento. Os tratamentos consistiram em: testemunha (nenhum tratamento pré-germinativo); sementes com corte em bisel na parte distal, formando uma fenda; sementes coletadas de fezes de ruminantes, passadas pelo trato gastrointestinal; e sementes pré-embebidas em água destilada por 24 horas. Os dados foram submetidos à análise de variância e as médias comparadas pelo teste Tukey a $5 \%$. Os tratamentos pré-germinativos não propiciaram aumento na emergência das plântulas, pois a mesma iniciou-se aos 9 dias após a semeadura para todos os tratamentos estudados. As sementes que passaram pelo trato gastrointestinal de ruminantes e as pré-embebidas em água destilada por 24 horas tiveram redução de seu potencial germinativo. As sementes pré-embebidas em água destilada por 24 horas apresentarem-se mais pesadas e maiores, porém após a germinação produziram plântulas com menor peso de matéria fresca e seca em relação aos demais tratamentos.

PALAVRAS-CHAVE: Biometria de sementes, emergência, germinação, Spondias tuberosa.
ABSTRACT: One of the factors that affect the spread of umbuzeiro (Spondias tuberosa Arr. Câmara) is the numbness of its seeds, promoting a slow and uneven emergence. Thus, the aim of this study was to evaluate the possible methods for overcoming the numbness of umbuzeiro seeds (Spondias tuberosa Arr. Câmara), and their physical and physiological quality. The following tests and determinations were performed: Water content, 100 seed weight, length and width of seeds, seedling emergence, emergence rate index, fresh and dry weight of seedlings. The experimental design was completely randomized with four replications of 50 seeds per treatment. The treatments were: control (no pre-germination treatment); seeds with diagonal cut on the distal part forming a slit; seeds collected from feces of ruminants, passed by gastrointestinal tract and pre-soaked seeds in distilled water for 24 hours. Data were subjected to analysis of variance and means were compared by Tukey test at 5\%. The pre-germination treatments have caused an increase in seedling emergence because it began nine days after sowing for all treatments. The seeds that passed through the gastrointestinal tract of ruminants and pre-soaked in distilled water for 24 hours showed reduction in germination potential. The pre-soaked seeds in distilled water for 24 hours are shown to be heavier and larger, but after germination, seedlings were produced with smaller weights of fresh and dry compared to the other.

KEYWORDS: Biometrics seeds, emergence, germination, Spondias tuberosa 


\section{Introdução}

Pertencente à família Anarcadiaceae, o umbuzeiro (Spondias tuberosa Arr. Câmara) é uma fruteira adaptada às condições de estresse hídrico. Seus frutos, colhidos de forma extrativista, são a principal fonte de renda, em determinada época do ano, para milhares de famílias (LINS NETO et al., 2010). A Região Nordeste do Brasil e o norte de Minas Gerais são conhecidos pelas paisagens áridas de áreas castigadas pela falta de chuvas. Portanto, assim como o cajá-mirim (Spondias mombim) na Nigéria (ADEDOKUN et al., 2010), o umbuzeiro (Spondias tuberosa Arr. Câmara) apresenta elevada produção e procura nessas regiões, além de apresentar propriedades terapêuticas e se destacar entre as 48 espécies com maior importância relativa na caatinga (ALBUQUERQUE et al., 2007).

A propagação do umbuzeiro (Spondias tuberosa Arr. Câmara) é realizada normalmente por semente, que se encontra no interior do endocarpo, o qual é comumente chamado de caroço. Entretanto, a sua germinação é lenta e desuniforme, constituindo problema para a produção comercial de mudas (ARAÚJO et al., 2001; COSTA et al., 2001; SOUZA et al., 2005).

Um dos fatores que dificultam a propagação do umbuzeiro (Spondias tuberosa Arr. Câmara) em larga escala é a dormência presente em suas sementes (SOUZA et al., 2005). A porcentagem de germinação das sementes dessa espécie, geralmente, é de $30 \%$ a $40 \%$. Essas baixas taxas estão associadas à resistência mecânica do endocarpo à expansão do embrião, limitando a entrada de água e oxigênio. No entanto, quando as sementes têm a sua dormência superada e são plantadas superficialmente no solo, a porcentagem de germinação é superior a $80 \%$ (LOPES et al., 2009). Nesse sentido, Adriance e Brison (1980) salientaram que a pré-embebição das sementes de umbuzeiro (Spondias tuberosa Arr. Câmara) em água destilada tem sido considerada eficiente para a redução da dormência.

Campos (1986) recomendou efetuar um corte em forma de bisel na parte distal da semente de umbuzeiro (Spondias tuberosa Arr. Câmara), eliminando a resistência mecânica exercida pelo endocarpo e favorecendo, dessa forma, a uniformização da emergência.

Para Finkelstein et al. (2008), a dormência é considerada um mecanismo de defesa das sementes contra as variações do ambiente que dificultam ou impedem sua atividade metabólica normal durante determinados períodos em que também não há transcrição da mensagem genética. Essa atividade é reassumida somente depois da ação de estímulo ambiental específico ou quando as condições de germinação tornam-se favoráveis.

Para Lopes et al. (2009), o tipo de dormência presente nas sementes de umbuzeiro (Spondias tuberosa Arr. Câmara) é combinação entre dormência física e fisiológica. Nesse sentido, vale ressaltar que, para fomentar a produção de sementes de umbuzeiro (Spondias tuberosa Arr. Câmara), informações precisas sobre a qualidade e superação da dormência das sementes deverão ser buscadas pela pesquisa.

De acordo com Gondim et al. (1991), a principal vantagem das plântulas provenientes de sementes é a formação dos xilopódios, que ocorre durante os primeiros 30 dias após a germinação; esses são órgãos de reserva do sistema radicular que armazenam água e substâncias nutritivas. Vale ressaltar que as plantas provenientes de estacas mostram dificuldades para formar essas estruturas em sua fase inicial de desenvolvimento. Por ser uma dicotiledônea, as plantas originárias de semente formam raiz pivotante, portanto, plantas provindas de sementes são mais resistentes a tombamentos ocasionados por ventos fortes do que as advindas de estacas.

Diante do exposto, o presente estudo teve como objetivo avaliar os possíveis métodos para superação da dormência de sementes de umbuzeiro (Spondias tuberosa Arr. Câmara) e a qualidade física e fisiológica delas.

\section{Material e Métodos}

O experimento foi conduzido no Laboratório de Análise de Sementes do Departamento de Ciências Agrárias da Universidade Estadual de Montes Claros - Unimontes, Campus Janaúba, MG, em 2009.

Foram utilizadas sementes de umbuzeiro (Spondias tuberosa Arr. Câmara) produzidas no município de Nova Porteirinha, MG, $15^{\circ} 49^{\prime} 51,5^{\prime \prime} \mathrm{S}, 43^{\circ} 16^{\prime} 18,2^{\prime \prime} \mathrm{W}$, a uma altitude de aproximadamente 540 metros. A pluviosidade média da região é de aproximadamente $870 \mathrm{~mm}$, temperatura média anual de $24{ }^{\circ} \mathrm{C}$, insolação de 2.700 horas anuais e umidade relativa média de $65 \%$. O clima da região é classificado por Koeppen (1948) como Aw, tropical com inverno seco.

As sementes foram coletadas de frutos maduros colhidos no chão. A polpa foi retirada manualmente e as sementes foram postas para secar aà sombra. Após a coleta e limpeza manual das sementes, elas foram armazenadas por três meses sob condições ambientais, a seguir foram enviadas ao laboratório para a realização das análises.

$\mathrm{O}$ delineamento experimental utilizado foi inteiramente casualizado (DIC) com 4 repetições de 50 sementes por tratamento. Os tratamentos utilizados no experimento consistiram em: T1 - testemunha (nenhum tratamento pré-germinativo); T2 - sementes com corte em forma de bisel na parte distal, formando uma fenda; T3 - sementes coletadas de fezes de ruminantes (bovinos), que passaram pelo trato gastrointestinal (TGI); e T4 - sementes pré-embebidas em água destilada por 24 horas.

As avaliações das qualidades física e fisiológica das sementes foram realizadas após os tratamentos de superação de dormência por meio dos testes e determinações descritos a seguir.

$\mathrm{O}$ teor de água das sementes foi determinado conforme metodologia recomendada nas Regras para Análise de Sementes (BRASIL, 2009), utilizando o método da estufa, a $105 \pm 3{ }^{\circ} \mathrm{C}$, durante 24 horas, com três repetições de 20 sementes inteiras, sendo os resultados expressos em \% de água por massa de semente.

Para o cálculo da massa de 100 sementes, foram utilizadas 4 repetições de 100 sementes por tratamento, que foram pesadas em balança analítica, apresentando-se os resultados médios. Ainda foram determinados o comprimento (em sentido longitudinal) e largura (em sentido transversal) das sementes, por meio de um paquímetro digital com precisão de 0,001 milímetro. 
A emergência de plântulas foi conduzida sob condições ambientais controladas de laboratório, sendo a areia anteriormente lavada e esterilizada em estufa a $200^{\circ} \mathrm{C}$ durante duas horas. As sementes foram semeadas em bandejas plásticas com $3 \mathrm{~cm}$ de profundidade e o teor de água foi mantido com irrigações leves, diariamente (BRASIL, 2009). Os resultados foram obtidos pelo número de plântulas normais emergidas, determinado por ocasião do $14^{\circ}$ dia após a montagem do experimento. Após a emergência das plântulas e decorridos 24 dias de avaliações sucessivos à semeadura, foi determinada a massa fresca das plântulas. Com uma lâmina, cortou-se a base da planta rente ao solo, sendo elas acondicionadas em sacos de papel para secagem em estufa a $60 \pm 3{ }^{\circ} \mathrm{C}$, até atingirem peso constante. Para cada tratamento foi determinada a produção de matéria fresca e seca.

$\mathrm{O}$ índice de velocidade de emergência foi conduzido em conjunto com o teste de emergência de plântulas, anotando-se diariamente, no mesmo horário, o número de plântulas que apresentaram alça cotiledonar visível. Ao final do teste, com os dados diários do número de plântulas emergidas, foi calculado o índice de velocidade de emergência, empregando-se a fórmula proposta por Maguire (1962).

Os resultados foram submetidos à análise de variância e teste $\mathrm{F}$, sendo que as características significativas em nível de $5 \%$ foram submetidas ao teste Tukey, também em nível de $5 \%$ de significância.

\section{Resultados e Discussão}

O teor de água médio das sementes durante o experimento foi de $18,84 \%$ (Tabela 1). Houve uma grande variação no teor de água, ressaltando-se que os altos valores de umidade verificados no tratamento 4 registram-se em função da pré-embebição das sementes em água destilada por 24 horas.

Nesse sentido, Coimbra et al. (2007) ressaltam que o teor de água inicial das sementes é um fator primordial para a padronização dos testes de avaliação de qualidade a serem realizados e, consequentemente, para a obtenção de resultados consistentes. Vale ressaltar que, apesar da variação verificada na umidade das sementes provenientes do tratamento $4 \mathrm{em}$ relação aos demais tratamentos, o teor de água das sementes pré-embebidas em água destilada durante $24 \mathrm{~h}$ não favoreceu os resultados obtidos nas avaliações realizadas para a qualidade fisiológica das sementes.

Cavalcanti et al. (2006) encontraram valores de teor de água das sementes de umbuzeiro (Spondias tuberosa Arr. Câmara) próximos aos encontrados no presente trabalho para as sementes originadas do tratamento 4 , variando de $48 \%$ a $52 \%$, após as sementes ficarem imersas em água destilada por 12 horas.

Com relação à massa de 100 sementes (Tabela 1), verifica-se que os valores variaram de 145,02 g (T3) a 320,48 g (T4). Possivelmente, essa variação deu-se em função da total ausência das partes fibrosas nas sementes (restos de endocarpo) após passarem pelo trato gastrointestinal dos animais (T3), levando a valores inferiores na massa de 100 sementes. As sementes mais pesadas foram aquelas que apresentaram maior valor no teor de água em função do tratamento pré-germinativo
(T4), devido a uma maior aderência das moléculas de água às partes fibrosas, além de uma maior embebição pelo embrião da semente. Para as sementes que não receberam nenhum tratamento pré-germinativo (T1) e as que foram cortadas em formato de bisel (T2), os valores verificados na massa de 100 sementes foram de 173,66 g e 165,44 g, respectivamente.

Os resultados médios de emergência de plântulas (EP), índice de velocidade de emergência (IVE), matéria fresca (MF) e matéria seca (MS) de plântulas em função dos tratamentos são apresentados na Tabela 2. Todas as variáveis avaliadas apresentaram diferença significativa a $5 \%$ de probabilidade pelo teste $\mathrm{F}$.

Através do teste de emergência das plântulas (EP), observa-se que os maiores valores registraram-se com as sementes que não receberam nenhum tratamento pré-germinativo (testemunha) e nas provenientes do corte em forma de bisel, sendo que essas últimas não diferiram $(\mathrm{P}>0,05)$ estatisticamente dos demais tratamentos (Tabela 2). Campos (1986), estudando diferentes métodos de superação em sementes de umbuzeiro (Spondias tuberosa Arr. Câmara) verificou que o corte em formato de bisel sozinho foi suficiente para promover a germinação das sementes. Em adição, Aragão et al. (2008) concluíram que o corte em bisel na semente de umbuzeiro (Spondias tuberosa Arr. Câmara) proporcionou os melhores níveis de germinação, quando comparado aos demais tratamentos. Segundo esses autores, com esse procedimento há uma exposição do embrião ao ambiente exterior da semente e a entrada de água é completamente facilitada.

Tabela 1. Teores médios de água (\%) e peso de 100 sementes (g) de umbu, em função dos tratamentos.

\begin{tabular}{ccccc}
\hline \multirow{2}{*}{ Itens } & \multicolumn{4}{c}{------ Tratamentos------- } \\
\cline { 2 - 5 } & $\mathrm{T} 1$ & $\mathrm{~T} 2$ & $\mathrm{T3}$ & $\mathrm{T4}$ \\
\hline Teor de água (\% b.u.) & $\mathbf{8 , 5 8}$ & $\mathbf{8 , 5 0}$ & $\mathbf{8 , 6 6}$ & 49,55 \\
Peso de 100 sementes $(\mathrm{g})$ & $\mathbf{1 7 3 , 6}$ & $\mathbf{1 6 5 , 4}$ & $\mathbf{1 4 5 , 0}$ & $\mathbf{3 2 0 , 4}$ \\
\hline
\end{tabular}

T1: Testemunha; T2: Sementes com corte em bisel; T3: Sementes passadas pelo trato gastrointestinal; T4: Sementes embebidas em água destilada por 24 horas.

Tabela 2. Resultados médios de emergência de plântulas (EP), índice de velocidade de emergência (IVE), matéria fresca (MF) e matéria seca (MS) de plântulas de umbu aos 24 dias após a semeadura em função dos tratamentos.

\begin{tabular}{|c|c|c|c|c|}
\hline \multirow{2}{*}{ Itens } & \multicolumn{4}{|c|}{------- Tratamentos -------- } \\
\hline & T1 & $\mathbf{T} 2$ & T3 & T4 \\
\hline EP (\%) & 54,50 a & $47,00 \mathrm{ab}$ & $38,50 \mathrm{~b}$ & $41,50 \mathrm{bc}$ \\
\hline IVE & 2,55 a & $2,06 \mathrm{ab}$ & $1,35 \mathrm{c}$ & $2,04 \mathrm{bc}$ \\
\hline MF (g) & 24,31 a & 19,03 ab & $9,71 \mathrm{c}$ & 17,29 b \\
\hline MS (g) & 3,07 a & $2,54 \mathrm{ab}$ & $1,57 \mathrm{c}$ & $2,21 \mathrm{bc}$ \\
\hline
\end{tabular}

T1: Testemunha; T2: Sementes com corte em bisel; T3: Sementes passadas pelo trato gastrointestinal; T4: Sementes embebidas por 24 horas. Médias seguidas pela mesma letra na linha não diferem entre si ao nível de $5 \%$ de probabilidade pelo teste Tukey. 
Segundo Marcos Filho (2005) a escarificação mecânica em sementes de umbuzeiro (Spondias tuberosa Arr. Câmara) facilita a expansão do embrião ou, ainda, a liberação de substâncias inibidoras solúveis em água presentes na região interna ao endocarpo para o ambiente. Ainda em suas considerações, Lopes et al. (2009) ressaltaram que provavelmente há mais de um mecanismo de dormência no caso do umbuzeiro (Spondias tuberosa Arr. Câmara), conforme relatado por Lederman et al. (1989).

As sementes que passaram pelo trato gastrointestinal dos ruminantes (T3) e as pré-embebidas em água destilada por 24 horas (T4) apresentaram valores inferiores na porcentagem de plântulas normais verificada através do teste emergência das plântulas. Costa et al. (2001), estudando o estádio de maturação das sementes de umbuzeiro (Spondias tuberosa Arr. Câmara) em diferentes tempos de pré-embebição em água ( 0 horas; 48 h; 96 h e 114 h), concluíram não haver influência dos períodos de imersão em água sobre a germinação das sementes.

A emergência das plântulas de umbuzeiro (Spondias tuberosa Arr. Câmara) iniciou-se aos 9 dias após a semeadura para todos os tratamentos estudados. Entretanto, essa constatação não foi verificada por Araújo et al. (2001), que registraram que a emergência de plântulas de umbuzeiro (Spondias tuberosa Arr. Câmara) iniciou-se aos 16 dias após a semeadura. Já Aragão et al. (2008), estudando diferentes métodos para superação de dormência em sementes de umbuzeiro (Spondias tuberosa Arr. Câmara) produzidas em Natal, RN, verificaram que a emergência das sementes começou a partir do $12^{\circ}$ dia após o semeio. Possivelmente, as diferenças nas condições climáticas de uma região para outra, e no histórico das sementes utilizadas, podem ter interferido nos resultados encontrados.

Por meio do teste EP os maiores valores na porcentagem de plântulas normais aos 24 dias após a semeadura, verificaram-se para as sementes que não receberam nenhum tratamento e para aquelas cortadas em formato bisel, rressaltando que, durante o período, aproximadamente $25 \%$ das sementes já haviam germinado (Tabela 2). Entretanto, Brito Neto et al. (2009), trabalhando com a cultura do umbuzeiro (Spondias tuberosa Arr. Câmara), verificaram que aos 15 dias após a semeadura apenas $10 \%$ das plântulas haviam emergido e somente após 120 dias de semeadura as sementes atingiram um percentual cumulativo de $90 \%$ de germinação, confirmando a lentidão e a desuniformidade do processo de germinação de sementes dessa espécie, conforme relatado por Campos (1986).

Lopes et al. (2009) verificaram que sementes recém-colhidas de umbuzeiro (Spondias tuberosa Arr. Câmara) não germinaram, e aquelas armazenadas por 3 meses germinaram cerca de $56,9 \%$, valores esses semelhantes aos encontrados no presente trabalho para as sementes originadas do tratamento 1 (Tabela 2). Ainda segundo esses autores, as melhores épocas que proporcionaram incrementos na porcentagem de germinação das sementes compreendem os períodos de 120 a 210 dias após a colheita dos frutos, alcançando $83 \%$ de germinação e os maiores percentuais de velocidade de germinação. Nesse sentido, Araújo et al. (2001) relatam que o período entre a colheita das sementes de umbuzeiro (Spondias tuberosa Arr. Câmara) e a semeadura exerce importante influência tanto na porcentagem como na velocidade de germinação.

Os resultados obtidos por meio do índice de velocidade de emergência (IVE) indicaram que as sementes provenientes do tratamento 1 diferiram $(\mathrm{P}<0,05)$ dos demais tratamentos, apresentando maiores índices. As sementes cortadas em formato bisel e as pré-embebidas em água destilada por 24 horas apresentaram comportamento semelhante, não diferindo $(P>0,05)$ entre si, atingindo valores intermediários no IVE. As sementes que passaram pelo trato gastrointestinal dos ruminantes apresentaram resultados inferiores (Tabela 2). Os maiores índices verificados através do IVE foram de 2,55 para as sementes que não receberam tratamento. Entretanto, para as sementes que passaram pelo trato gastrointestinal de ruminantes (TGI) verificaram-se reduções numéricas acentuadas, obtendo-se valores de 1,35 no IVE. Lopes et al. (2009), trabalhando com sementes de umbuzeiro, verificaram que os maiores índices obtidos foram de 2,65, porém somente após 6 meses de armazenamento.

Nesse sentido, Araújo et al. (2016) afirmam que para obter o índice de emergência satisfatório ( $>74 \%$ ), deve-se considerar o tempo de armazenamento das sementes ( 24 meses), a abertura do endocarpo interno e a embebição delas. $\mathrm{O}$ que não foi considerado no presente estudo.

Os resultados de matéria fresca de plântulas apresentaram comportamento semelhante aos resultados obtidos na emergência das plântulas, sendo que as sementes que não receberam nenhum tratamento pré-germinativo e as que foram cortadas em formato bisel apresentaram resultados superiores. As sementes que passaram pelo TGI (T3) apresentaram resultados intermediários, não diferindo $(P>0,05)$ estatisticamente das sementes com corte em bisel. Porém os resultados de matéria fresca de plântulas foram inferiores para as sementes pré-embebidas em água por $24 \mathrm{~h}$ (Tabela 2).

Os resultados de matéria seca de plântulas indicaram novamente superioridade nas sementes que não receberam nenhum tratamento e nas que foram cortadas em formato bisel (Tabela 2). As sementes pré-embebidas em água por $24 \mathrm{~h}$ apresentaram resultados intermediários, não deferindo $(\mathrm{P}>0,05)$ estatisticamente das sementes que passaram pelo TGI (T3), que apresentaram valores inferiores.

De uma maneira geral, os resultados indicaram que apenas as sementes que receberam um corte em forma de bisel apresentaram resultados semelhantes à testemunha. Entretanto, para os demais tratamentos foram verificadas reduções numéricas nas variáveis analisadas, confirmando a ineficiência dos tratamentos. Possivelmente, ao passar pelo TGI dos ruminantes as sementes podem ter sido danificadas, tendo a sua viabilidade prejudicada. Para as sementes pré-embebidas, provavelmente o tempo de embebição não foi suficiente para favorecer a germinação durante o experimento. Nesse sentido, Costa et al. (2001) revelam que as sementes de umbuzeiro (Spondias tuberosa Arr. Câmara) provenientes de frutos maduros apresentam maior dificuldade de penetração de água, imposta pela terceira camada (que está em contato com a semente), por ela ser lignificada e não apresentar perfurações. 
Tabela 3. Resultados médios das características físicas comprimento (COMP) e largura (LARG) de sementes de umbu em função dos tratamentos estudados.

\begin{tabular}{ccccc}
\hline \multirow{2}{*}{ Itens } & \multicolumn{4}{c}{------- Tratamentos ------} \\
\cline { 2 - 5 } & T1 & T2 & T3 & T4 \\
\hline COMP $(\mathrm{mm})$ & 22,56 a & 22,01 a & 20,28 b & 22,59 a \\
LARG $(\mathrm{mm})$ & 16,60 a & 12,89 c & 14,28 b & 16,57 a \\
\hline
\end{tabular}

T1: Testemunha; T2: Sementes com corte em bisel; T3: Sementes passadas pelo trato gastrointestinal; T4: Sementes embebidas por 24 horas. Médias seguidas pela mesma letra na linha não diferem entre si ao nível de $5 \%$ de probabilidade pelo teste Tukey.

Na Tabela 3 constam os resultados médios das características físicas comprimento (COMP) e largura (LARG) de sementes de umbuzeiro (Spondias tuberosa Arr. Câmara) em função dos tratamentos estudados. Houve efeito $(\mathrm{P}<0,05)$ de tratamento para as variáveis comprimento e largura de sementes.

Verifica-se que as sementes que não receberam nenhum tratamento pré-germinativo, as cortadas em formato bisel e as pré-embebidas em água por $24 \mathrm{~h}$ apresentaram resultados superiores no comprimento em relação àquelas que passaram pelo trato gastrointestinal de ruminantes (Tabela 3 ). Porém os resultados de largura de sementes mostraram superioridade para as sementes que não foram tratadas (testemunha) e as embebidas em água por $24 \mathrm{~h}$. As sementes provenientes do T3 (TGI) apresentaram resultados intermediários. Já as sementes que receberam um corte em forma de bisel apresentaram resultados inferiores na variável largura de sementes.

As sementes apresentaram comprimento variando de $2,03 \mathrm{~cm}$ a 2,26 cm e largura de $1,29 \mathrm{~cm}$ a $1,66 \mathrm{~cm}$ (Tabela 3). Carvalho e Nakagawa (2000) afirmam que as sementes de maior tamanho são mais bem nutridas durante o seu desenvolvimento, possuindo embriões bem formados e com maior quantidade de substâncias de reserva, que para o umbuzeiro (Spondias tuberosa Arr. Câmara) tem predominância de lipídios e proteínas (BORGES et al., 2007), sendo classificadas como aleuro-oleaginosas.

\section{Conclusões}

Os tratamentos pré-germinativos não propiciaram aumento na emergência das plântulas.

As sementes que passaram pelo trato gastrointestinal de ruminantes e as pré-embebidas em água destilada por 24 horas tiveram redução de seu potencial germinativo.

As sementes pré-embebidas em água destilada por 24 horas apresentarem-se mais pesadas e maiores, porém após a germinação produziram plântulas com menor peso de matéria fresca e seca em relação aos demais tratamentos.

\section{Referências}

ADEDOKUN, M. O.; OLADOYE, A. O.; OLUWALANA, S. A. Socio-economic importance and utilization of Spondias mombin in Nigéria. Asian Pacific Journal of Tropical Medicine, Mumbai, v. 3, n. 3, p. 232-234, 2010.

ADRIANCE, G. W.; BRISON, F. R. Propagation of Horticultural Plants. 2nd ed. Bombay Tata: McGraw-Hill, 1980. 289 p.
ALBUQUERQUE, U. P. et al. Medicinal plants of the caatinga (semiarid) vegetation of NE Brazil: A quantitative approach. Journal of Ethnopharmacology, Lausanne, v. 114, n. 3, p. 325-354, 2007.

ARAGÃO, F. A. S.; SOUZA, F. X.; TORRES, S. B. Otimização da quebra de dormência de sementes de umbu. In: CONGRESSO BRASILEIRO DE FRUTICULTURA, 20., 2008, Vitória, ES. Anais... Vitória: SBF, 2008. 1 CD-ROM.

ARAÚJO, F. P.; SANTOS, C. A. F.; CAVALCANTI, N. B. et al. Influência do período de armazenamento das sementes de umbuzeiro na sua germinação e no desenvolvimento da plântula. Revista Brasileira de Armazenamento, Viçosa, v. 1, n. 26, p. 36-39, 2001.

ARAÚJO, F. P. et al. Propagação e manejo. In: DRUMOND, M. A.; AIDAR, S. T.; NASCIMENTO, C. E. S. et al. (Ed.). Umbuzeiro: avanços e perspectivas. 1. ed. Petrolina: Embrapa Semiárido, 2016. p. 149-175.

BORGES, S. V. et al. Chemical composition of umbu (Spondias tuberosa Arr. Cam) seeds. Quimica Nova, São Paulo, v. 30, n. 1, p. 49-52, 2007.

BRASIL. Ministério da Agricultura, Pecuária e Abastecimento. Secretaria de Defesa Agropecuária. Regras para Análise de Sementes. Brasília: Mapa/ACS, 2009. 399 p.

BRITO NETO, J. F. et al. Emergência de plântulas e características morfológicas de sementes e plantas de umbuzeiro. Engenharia Ambiental, Espírito Santo do Pinhal, v. 6, n. 2, p. 224-230, 2009.

CAMPOS, C. O. Estudos da quebra de dormência da semente do umbuzeiro (Spondias tuberosa, Arr. Camara). 1986. $71 \mathrm{f}$. Dissertação (Mestrado em Agronomia)-Universidade Federal do Ceará, Ceará, 1986.

CARVALHO, N. M.; NAKAGAWA, J. Sementes: ciência, tecnologia e produção. 4 ed. Jaboticabal: Funep, 2000. 588 p.

CAVAlCANTI, N. B.; RESENDE, G. M.; DRUMOND, M. A. Período de dormência de sementes de umbuzeiro. Revista Caatinga, Mossoró, v. 19, n. 2, p. 135-139, 2006.

COIMBRA, R. A. et al. Teste de germinação com acondicionamento dos rolos de papel em sacos plásticos. Revista Brasileira de Sementes, v. 29, n. 1, p. 92-97, 2007. Disponível em: <http://www.scielo.br/ pdf/rbs/v29n1/13.pdf >. Acesso em: 22 mai. 2015.

COSTA, N. P. et al. Efeito do estádio de maturação do fruto e do tempo de pré-embebição de endocarpos na germinação de sementes de umbuzeiro (Spondias tuberosa Arr. Câm.). Revista Brasileira de Fruticultura, Jaboticabal, v. 23, n. 3, p. 738-741, 2001.

FINKELSTEIN, R. et al. Molecular aspects of seed dormancy. Annual Review of Plant Biology, Palo Alto. v. 59, p. 387-415, 2008.

GONDIM, T. M. S. et al. Período de ocorrência de formação de xilopódios em plantas de umbu (Spondias tuberosa Arr. Câm.) propagadas sexuada e assexuadamente. Revista Brasileira de Fruticultura, Jaboticabal, v. 13, n. 2, p. 33-38, 1991.

KOEPPEN, W. Climatologia. Tradução de Pedro R.H. Perez. Buenos Aires: Grafica Panamericana, 1948. 478 p.

LEDERMAN, E. I.; NETO, L. G.; BEZERRA, J. E. F. B. Indução da germinação de sementes de umbu (Spondias tuberosa arr. Cam.) através de tratamentos físicos, químicos e mecânicos. Revista Brasileira de Fruticultura, Jaboticabal, v. 11, n. 3, p. 27-32, 1989.

LINS NETO, E. M. F.; PERONI, N.; ALBUQUERQUE, U. P. Traditional knowledge and management of Umbu (Spondias tuberosa, Anacardiaceae): an endemic species from the Semi-Arid 
region of northeastern Brazil. Economic Botany, Bronx, v. 64, n. 1, p. 11-21, 2010.

LOPES, P. S. N.; MAGALHÃES, H. M.; GOMES, J. G. et al. Superação de sementes de umbuzeiro (Spondias tuberosa, Arr. Câm.) utilizando diferentes métodos. Revista Brasileira de Fruticultura, Jaboticabal, v. 31, n. 3, p. 872-880, 2009.

MAGUIRE, J. A. Speed of germination: aid in selection an evaluation for seedling emergence and vigor. Crop Science, Madison, v. 2, n. 2, p. 176-177, 1962.
MARCOS FILHO, J. Fisiologia de sementes de plantas cultivadas. In: JULHO, M.F. Dormência de sementes. Piracicaba: Fealq, p. 253-287. 2005

SOUZA, A. A. et al. Seeds of Spondias tuberosa originated from fruits harvested at four maturation stages and stored. Revista Brasileira de Engenharia Agrícola e Ambiental, Campina Grande, v. 9, n. 3, p. 372-378, 2005.

Recebido: 11 jun 2015 Aprovado: 18 set. 2017 